\title{
DESIGN AND PERFORMANCE ANALYSIS OF LOW PASS FIR FILTER USING HAMMING AND KAISER WINDOWS
}

\author{
Ghulam Ahmad Raza ${ }^{1}$, Md. Jafir Alam² \\ ${ }^{1}$ Assistant Professor, Department of Electronics \& Communication Engineering, Siwan Engineering \& Technical \\ Institute, Siwan, Bihar, India \\ ${ }^{2}$ Assistant Professor, Department of Electronics \& Communication Engineering, Siwan Engineering \& Technical \\ Institute, Siwan, Bihar, India
}

\begin{abstract}
Digital Signal Processing is used in many areas where analogue method was difficult. Filters are used to separate or combine different frequencies. In this paper low pass filter has been designed and simulated using different windows techniques. Hamming and Kaiser Windows techniques are used along with Rectangular window technique for the design analysis by using matlabs. The performances of all the designs have been compared in terms of sidelobe attenuation and mainlobe width. The simulated result shows that the Kaiser window has near optimum performance and having the simplest implementation. The result also shows that increasing the Kaiser Window parameter Beta widens the mainlobe and decreases the amplitude of sidelobes
\end{abstract}

Keywords: DSP, FIR Digital Filter, Hamming Window, Kaiser Window and Rectangular window

\section{INTRODUCTION}

DSP is used in different areas such as image processing, spectrum analysis, speech synthesis, sonar processing, data communication etc. DSP system can be programmed and reprogrammed without changing in hardware. It has many advantages such as accuracy, perfect reproducibility, greater flexibility and superior performance. The signal used in DSP is derived from analog signal which have sampled at certain interval to convert into digital signal [1]. Digital filters are important class of Linear time invariant DSP system designed to modify the frequency characteristics of the input signal $x(n)$ to meet certain specific design requirements. Digital filters have emerged as a strong option for removing noise, shaping spectrum and minimizing inter-symbol interference (ISI) in communication architectures [2]. Digital filters have been classified into Finite Impulse response (FIR) and Infinite Impulse Response (IIR) filters. The FIR has an impulse response $h(n)$ of finite duration, defined over the interval $0 \leq \mathrm{m} \leq \mathrm{M}$ has finite number of terms,

$$
\mathrm{y}(\mathrm{n})=\sum_{m=0}^{M} \mathrm{~h}(\mathrm{~m}) \cdot \mathrm{x}(\mathrm{n}-\mathrm{M})
$$

An IIR filter has an impulse response $h(n)$ of infinite duration, defined over the infinite interval $0 \leq n \leq \infty$, now has infinite number of terms.

$$
y(n)=\sum_{m=0}^{\infty} h(m) \cdot x(n-M)
$$

\section{FIR DESIGN METHODS}

The simplest method of FIR filter design is called the window method. This method begins with an ideal desired frequency response which is represented as

$$
\mathrm{H}_{\mathrm{d}}(\mathrm{w})=\sum_{n=0}^{\infty} h_{d}(\mathrm{n}) e^{-j w n}
$$

Where

$$
\mathrm{h}_{\mathrm{d}}(\mathrm{n})=\frac{1}{2 \pi} \int_{-\pi}^{\pi} H_{\mathrm{d}}(\mathrm{w}) \mathrm{e}^{\mathrm{jwn}} \mathrm{dw}
$$

Some of windows commonly used are Blackman Window, Blackman-Haris window, Bohman window, Chebyshew window, Flat Top window, Gaussian window, Hamming window, Hanning window, Nuttall window, Kaiser Window, Rectangular window, Taylor window and Triangular window.

To eliminate the some pass band and stop band ripples, Hamming window technique is used [3]. The coefficients of a Hamming window are computed from the equation (5)

$$
\mathrm{w}(\mathrm{n})=0.54-0.46 \cos \left(2 \pi \frac{n}{N}\right), 0 \leq \mathrm{n} \leq \mathrm{N}
$$

Kaiser window has an adjustable shape parameter that allows the window to achieve any desired value of ripple or attenuation. The Kaiser window is unique that it has near optimum performance, in the sense of minimizing the sidelobe energy of the window as well as having the simplest implementation [4]. Kaiser window depends on two parameters, $\mathrm{N}$ and the shape parameter $\alpha$. The equation of Kaiser Window is expressed in equation (6). 


$$
w(n)=\frac{I_{0}\left(\alpha \sqrt{1-(n-M)^{2} / M^{2}}\right.}{I_{0}(\alpha)}
$$

Kaiser window is also defined in terms of $\beta$, where $\beta$ is the Kaiser Window parameter that affects the sidelobe attenuation of the Fourier transform of the window [5].

The Kaiser window that design an FIR filter with sidelobe attenuation of $\alpha \mathrm{dB}$ is expressed as

$$
\beta=\left\{\begin{array}{cc}
0.1102(\alpha-8.7), & \alpha>50 \\
\left.0.5842(\alpha-21)^{0.4}\right) & \\
+0.07886(\alpha-21), & 50 \geq \alpha \geq 21 \\
0, & \alpha<21
\end{array}\right.
$$

A rectangular window is equivalent to not using any window because the rectangular function just truncates the signal to within a finite time interval. This window has the highest amount of spectral leakage. The rectangular window has a value of one over its length. The weighting function for the Rectangular window is to be defined [6] by

$$
\begin{aligned}
& \mathrm{W}_{\mathrm{R}}(\mathrm{n})=1, \text { for }|\mathrm{n}| \leq \frac{M-1}{2} \\
& \mathrm{w}_{\mathrm{R}}(\mathrm{n})=0, \text { otherwise }
\end{aligned}
$$

\section{DESIGN SIMULATIONS}

Table 1: Parameter Specification

\begin{tabular}{|l|l|}
\hline Parameter & Values \\
\hline Sampling Frequency & $48000 \mathrm{~Hz}$ \\
\hline Cutoff Frequency & $10800 \mathrm{~Hz}$ \\
\hline Order & 50 \\
\hline$\beta$ & $\beta=1,5,7$ (For Kaiser Window) \\
\hline
\end{tabular}

Table 1 show the parameter specification of three windows for the designing of lowpass filter by using Rectangular, Hamming and Kaiser Windows.

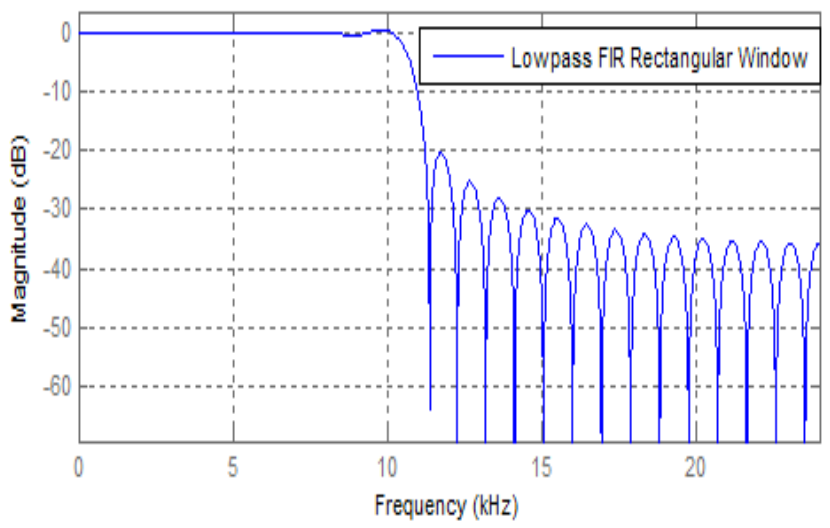

Fig 1: Lowpass FIR filter using Rectangular window

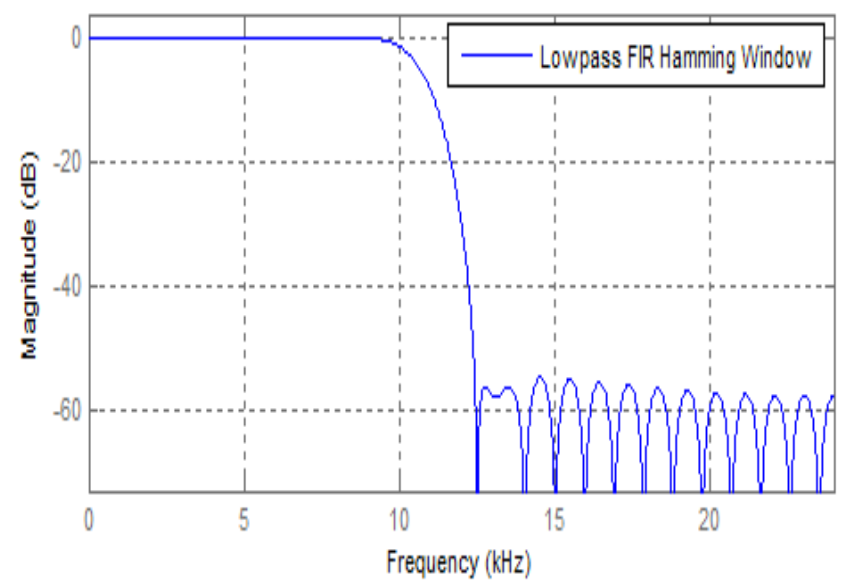

Fig 2: Lowpass FIR filter using Hamming window

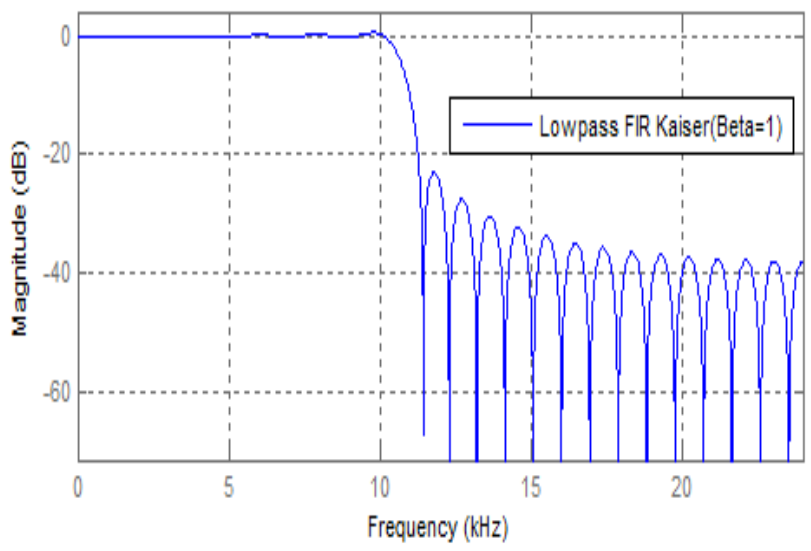

Fig 3: Lowpass FIR filter using Kaiser Window $(\beta=1)$

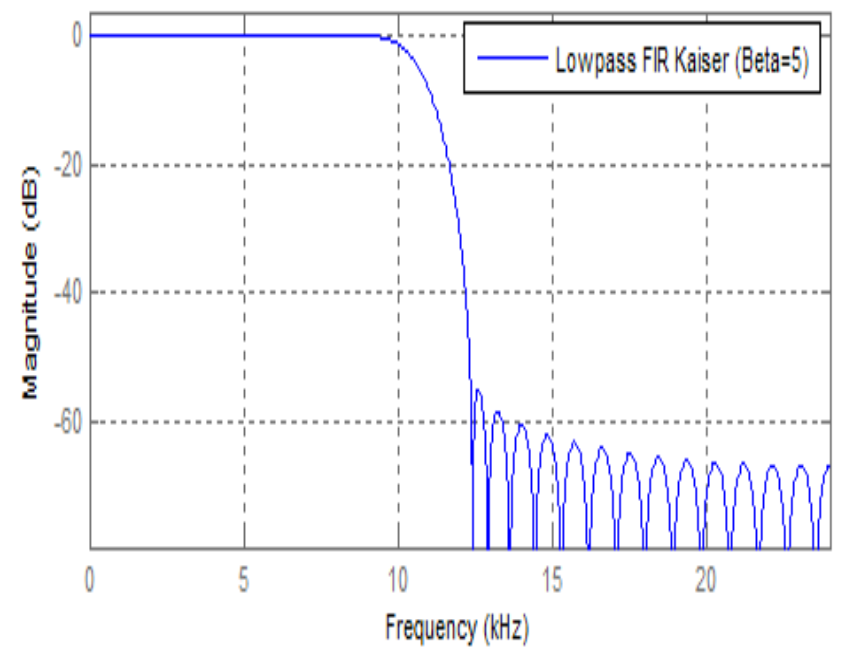

Fig 4: Lowpass FIR filter using Kaiser Window $(\beta=5)$ 


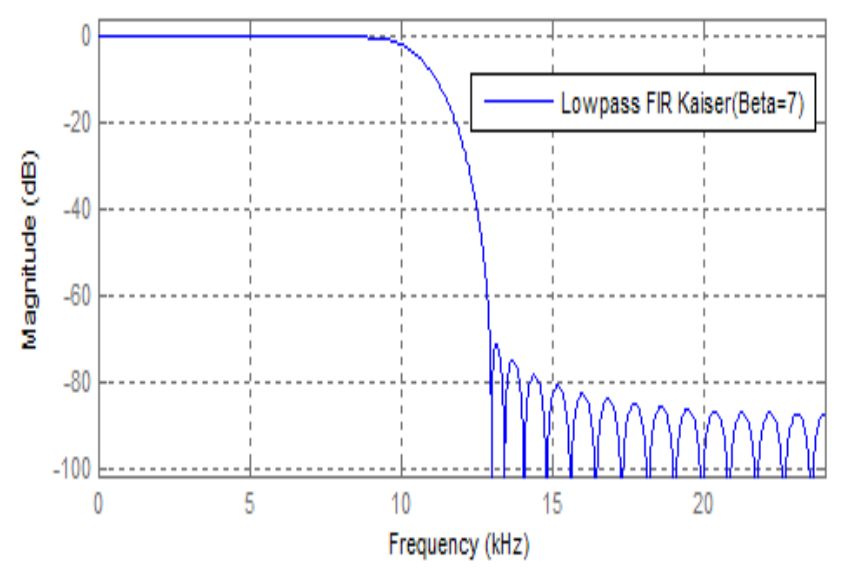

Fig 5: Lowpass FIR filter using Kaiser Window $(\beta=7)$

Figure $1 \& 2$ show the magnitude and frequency response of Lowpass FIR filter using Rectangular and Hamming window. Figure 3, 4, and 5 show Kaiser Window at $\beta=1$, $\beta=5$ and $\beta=7$ respectively.

\section{COMPARATIVE ANALYSIS}

Hamming and Kaiser Windows techniques are used along with Rectangular window for design analysis and compared these three windows. Table 2 shows the comparison of these three windows in terms of leakage factor, relative sidelobe attenuation and mainlobe width. The leakage factor is minimum and mainlobe width is maximum of Kaiser Window than the Hamming window.

Table 2: Matlab simulated result of Rectangular, Hamming and Kaiser Windows.

\begin{tabular}{|l|l|l|l|}
\hline Windows & $\begin{array}{l}\text { Leakage } \\
\text { Factor }\end{array}$ & $\begin{array}{l}\text { Relative } \\
\text { Sidelobe } \\
\text { attenuation }\end{array}$ & $\begin{array}{l}\text { Main lobe } \\
\text { width } \\
(-3 \mathrm{~dB})\end{array}$ \\
\hline Rectangular & $9.25 \%$ & $-13.3 \mathrm{~dB}$ & 0.035156 \\
\hline Hamming & $0.04 \%$ & $-42.3 \mathrm{~dB}$ & 0.050781 \\
\hline Kaiser $(\beta=1)$ & $6.47 \%$ & $-14.7 \mathrm{~dB}$ & 0.035156 \\
\hline Kaiser $(\beta=5)$ & $0.02 \%$ & $-37.4 \mathrm{~dB}$ & 0.050781 \\
\hline Kaiser $(\beta=7)$ & $0 \%$ & $-50.9 \mathrm{~dB}$ & 0.058594 \\
\hline
\end{tabular}

\section{CONCLUSIONS}

In this paper lowpass filter has been designed and simulated using Rectangular, Hamming and Kaiser Windows techniques. Lowpass filter has been designed for the different value of Kaiser Window parameter $\beta$. It has been compared leakage factor, mainlobe width and relative sidelobe attenuation of the three windows from the simulated result. . The result show that increasing the value of Kaiser Window parameter $\beta$ widens the mainlobe and decrease the amplitude of sidelobes that is increases the attenuation. The relative side lobe attenuation of Kaiser Window is $-50.9 \mathrm{~dB}$ and mainlobe width of this window $(-3 \mathrm{~dB})$ is 0.058594 at sampling frequency $48000 \mathrm{~Hz}$, cut off frequency $10800 \mathrm{~Hz}$ and order 50. The simulated result also shows that Kaiser window has greater mainlobe width and less leakage factor in comparison of Hamming window.

\section{ACKNOWLEDGEMENTS}

Authors would like to thank the Hon'ble Chairman, Dr. Md. Shahabuddin, Secretary and Director, Siwan Engineering \& Technical Institute, Siwan, India. authors also would like to thank the Director-In-Charge, Dr. Noruddin Ansari, for his constant inspirations and support throughout this research work.

\section{REFERENCES}

[1]. Emmanuel C. Ifeacher, Barrie W.Jervis "Digital Signal Processing”, Second Edition, Pearson Publication, pp. 0240, 2004

[2]. Keshab.K.Parhi, "VLSI Digital Signal Processing Systems Design and Implementation". First edition, A Wiley-Interscience Publication, pp. 10-50, 1999

[3]. F. J. Harris, "On the use of Windows for Harmonic Analysis with the Discrete Fourier Transform", Proc. IEEE, 1978

[4]. Sophocles J.Orfanidis, "Introduction to Signal Processing” Prentice Hall, First Edition, pp.532-558, 1996

[5]. Kaiser, J.F, "Nonrecursive Digital Filter Design Using the IO-Sinh Window Function", Proc. IEEE symp. Circuit and Systems, pp.20-23, 1974

[6]. S Salivahanan, C Gnanapriya, "Digital Signal Processing, Second Edition, Mc Graw Hill, pp.445 -475, 2011

\section{BIOGRAPHIES}

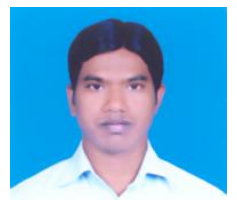

Ghulam Ahmad Raza received the Bachelors of Technology degree in Electronics \& Communication Engineering from Maulana Azad College of Engineering \& Technology Patna, India in 2009. He is pursuing M.E in Electronics \& Communication Engineering from National Institute of Technical Teachers' Training \& Research, Ministry of Human Resource Development, Panjab Univsrsity, Chandigarh, India.

$\mathrm{He}$ is an Assistant Professor in the Department of Electronics \& Communication Engineering, Siwan Engineering \& Technical Institute Siwan, Bihar, India. His current research and teaching interests are in DSP, Communication System and Microwave Engineering. 
Md. Jafir Alam received the Bachelors of Technology degree in Electronics \& Communication Engineering from Maulana Azad College of Engineering \& Technology Patna, India in 2007. He is pursuing M.E in Electronics and Communication Engineering from National Institute of Technical Teachers' Training \& Research, Ministry of Human Resource Development, Panjab Univsrsity, Chandigarh, India.

$\mathrm{He}$ is an Assistant Professor in the Department of Electronics \& Communication Engineering, Siwan Engineering \& Technical Institute Siwan, Bihar, India. His current research and teaching interests are in Signal and Systems, Digital Communication and Digital Electronics. 